\title{
Analysis of the Bank Customer Behavior Based on Conduction Change
}

\author{
Shiming Liu, Huihong Chen \\ Guangzhou Panyu Polytechnic \\ GuangZhou, China
}

\begin{abstract}
In order to improve the competitive advantage of the banking sector, adapt to the economic globalization and attract more customers to achieve the benefit maximization, this article analyses the bank customer behavior and researches the positive influence of customer behavior analysis on the bank. This paper uses conduction transformation theory to analyze the change of customer behavior characteristics that cause positive changes like higher deposit rates and lower loan interest rates. By calculating the electrical conductivity, it is concluded that a bank behavior influences on customer behavior. By calculating the correlation of customer behavior characteristics, we can get the impact of some changes in customer behavior on bank profits. Finally, the research results show that customer behavior analysis can enable banks have an impact on the positive changes in the market.
\end{abstract}

Keywords-extension; conduction change; bank market; customer behavior analysis

\section{INTRODUCTION}

With the in-depth application of computer technology and Internet technology, some new savings methods have risen rapidly in the financial market. Alipay, Yu Ebao and other savings methods allow a large number of social deposits to be transferred from traditional banks to the Internet financial industry. The Internet Finance poses an impact on traditional banks. What's worse, the banks face enormous challenges due to the financial crisis. Under various shocks, traditional banks attract customers by changing interest rates, adjusting the business structure and improving service level, so as to gain advantages and profits in the fierce competition.

The main idea of extensibility is to solve contradiction through conduction transformation. It is a very important extension transformation ${ }^{[1-2]}$, which starts from the relativity and implication of things and uses the conduction effect between primitives to solve contradictions. It is more appropriate to describe that a slight move in one part may affect the situation as a whole because there are various correlations between things. A transformation causes not only the change of its object of action but also the change of its related object because of conduction. The former transformation is called active transformation, and the latter is called conduction transformation of the former ${ }^{[3-5]}$.

Taking the bank as an example, under the active transformation of raising the deposit interest rate and lowering loan interest rate, this paper uses the theory of conduction

Guangdong Province Philosophy and Social Science Planning Project (GD18XGL40)

Guangzhou City Philosophy and Social Science Planning Project (2019GZGJ250) transformation to analyze the transformation of customers behavior characteristics caused by two kinds of active transformation adopted by the bank. By calculating the conductivity, we can get the influence degree of bank's active change behavior on customer's behavioral characteristics. By calculating the correlation of customer behavior characteristics, this paper analyzes the impact of the change of bank customer behavior on the bank's income, hence obtaining the bank's decision of positive transformation.

\section{CONDUCTION TRANSFORM}

Let $W=\left\{\Gamma \mid \Gamma \in\left\{B, C_{0}, k, U\right\}\right\}$ where $\mathrm{T}$ is an extensive transformation set on $\mathrm{W}$, that $T=\{T \mid T: W \rightarrow P(W)\}$,

For

$$
\Gamma_{0} \in W, \varphi \in T, \varphi=\left(\Gamma_{0}, \Gamma_{0}^{\prime}\right)
$$

$$
\text { if it exists } \varphi_{1} \in T, \Gamma \in W, \varphi_{1}=\left(\Gamma, \Gamma^{\prime}\right),
$$

Let $\varphi \Rightarrow \varphi_{1}$, then $\varphi_{1}$ is called as the first order conduction transformation of $\varphi$, which abbreviated as conduction transformation and recorded as $T_{\varphi}$. Then we get $T_{\varphi} \Gamma=\Gamma^{\prime}$ and called $\varphi$ as active transformation ${ }^{[2]}$.

\section{A. Conductivity}

The specific information elements $I_{1}=\left(O_{1}, C_{1}, V_{1}\right)$ and $I_{2}=\left(O_{2}, c_{2}, v_{2}\right)$. If it exits active transformation:

$$
\varphi I_{1}=I_{1}^{\prime}=\left(O_{1}, C_{1}, v_{1}^{\prime}\right)
$$

For conduction transformation ${ }_{I_{1}} T_{I_{2}}$ for $I_{2}$, that $I_{2}$ becomes:

$$
I_{2}^{\prime}=\left(O_{2}, C_{2}, v_{2}^{\prime}\right)
$$

That

$$
{ }_{I_{1}} T_{I_{2}} I_{2}=\left(O_{2}, C_{2}, V_{2}{ }^{\prime}\right)=I_{2}{ }^{\prime}
$$

Then call:

$$
v_{2}^{\prime}-v_{2}
$$

as Conduction effect. Call 
$v_{1}^{\prime}-v_{1}$

as an active variable. Call

$$
\gamma=\frac{v_{2}^{\prime}-v_{2}}{\left|v_{1}^{\prime}-v_{1}\right|}
$$

as transform $\varphi$ 's Conductivity with respect to $I_{2}$.

When multiple active transformations lead to multiple conduction transformations, let $\mathrm{I}_{1}, \mathrm{I}_{2}$, ,. $\mathrm{I}_{\mathrm{h}}$ satisfy the conditions

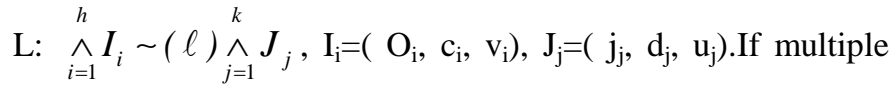
active transformations occur at the same time, that is $\wedge_{i=1}^{h} T_{I_{i}} I_{i}={ }_{i=1}^{k} I_{i}^{\prime}$, there must be conduction transformation ${ }_{\left(\wedge I_{i}\right)} T_{\left(\wedge J_{j}\right)}\left(\hat{j=1}_{j}^{k} J_{j}\right)=\wedge_{j=1}^{k} J_{j}^{\prime} \quad$ and when transformation $h$ $\wedge T_{i=1} \neq e$, the conductivity of this conduction knowledge for each conduction information element is

$$
\gamma_{j}=\frac{u_{j}^{\prime}-u_{j}}{\sum_{i=1}^{h} \lambda_{i}\left|v_{i}^{\prime}-v_{i}\right|}
$$

Among them, $u_{j}^{\prime}-u_{j}$ is conduction effect, and $v_{i}^{\prime}-v_{i}$ is an active variable:

$$
\sum_{i=1}^{h} \lambda_{i}=1
$$

\section{B. Support degree}

In (1), when $v_{2}^{\prime}-v_{2}>0$ is considered, the characteristic $\mathrm{C}_{2}$ corresponding to $v_{2}$ and $v_{2}^{\prime}$ is the positive conduction characteristic; when $v_{2}^{\prime}-v_{2}<0$, it is considered that the characteristic $\mathrm{C}_{2}$ corresponding to $v_{2}$ and $v_{2}^{\prime}$ is the negative conduction characteristic ${ }^{[2]}$.

In practical applications, sometimes the difference between the values before and after transformation is very small. For the need of practical problems, a threshold $\delta>0$ is given, and when $\left|v_{2}^{\prime}-v_{2}\right|>\delta$ is specified, the characteristic $\mathrm{C}_{2}$ corresponding to $\mathrm{V}_{2}$ is considered as the effective conduction feature. The support degree of conduction characteristic $C_{2}$ is:

$$
l_{i}=\frac{\text { Number of Effective Conduction Characteristics }}{\text { Total number of conduction features }}
$$

\section{CORRELATION FUNCTION}

In the extended set, the correlation function can objectively and quantitatively describe the process of quantitative and qualitative changes in things ${ }^{[2]}$. Different evaluation features have different forms of correlation functions. We must select correlation functions according to the requirements of specific issues.
In this paper, the author uses the elementary correlation function of the optimal point at the right end of the interval ${ }^{[2]}$. Let the quantitative and qualitative intervals of matter element characteristics

$X_{0}=\langle a, b\rangle, X=\langle c, d\rangle, x_{0} \in\langle a, b\rangle, x_{0} \neq \frac{a+b}{2}, X_{0} \subset X$, an d there is a common endpoint $x_{z}{ }^{[3]}$. For all $x \neq x_{z}$, the elementary correlation function is established:

$k(x)= \begin{cases}\frac{\rho_{r}\left(x, x_{0}, X_{0}\right)}{D\left(x, X_{0}, X\right)}, & \text { others } \\ \frac{\rho_{r}\left(x, x_{0}, X_{0}\right)}{D\left(x, X_{0}, X\right)}-1, & \rho(x, X)=\rho\left(x, X_{0}\right) \text { and } x \notin X_{0}\end{cases}$

Among that:

$D\left(x, X_{0}, X\right)=$

$\begin{cases}\rho(x, X)-\rho\left(x, X_{0}\right), & \rho(x, X) \neq \rho\left(x, X_{0}\right) \text { 且 } x \notin X_{0} \\ \rho(x, X)-\rho\left(x, X_{0}\right)+a-b, & \rho(x, X) \neq \rho\left(x, X_{0}\right) \text { 且 } x \in X_{0} \\ a-b, & \rho(x, X)=\rho\left(x, X_{0}\right)\end{cases}$

is the position relationship between point $x$ and interval sleeve composed of $X_{0}$ and $X$.

$$
\rho\left(x, X_{0}\right)=\left|x-\frac{a+b}{2}\right|-\frac{b-a}{2}= \begin{cases}a-x, & x \leq \frac{a+b}{2} \\ x-b, & x \geq \frac{a+b}{2}\end{cases}
$$

is the distance between point $\mathrm{x}$ and interval $\mathrm{X}$.

When $x_{0}=b$, then

$$
\rho_{r}\left(x, b, X_{0}\right)= \begin{cases}a-x, & x<b, \\ b_{z}, & x=b, \\ x-b, & x>b,\end{cases}
$$

Among that:

$b_{z}=\rho_{r}\left(b, b, X_{0}\right)= \begin{cases}0, & b \notin X_{0}, \\ a-b, & b \in X_{0}, \\ 0 \otimes(a-b), & b \notin X_{0} \text { and } b \in X_{0}\end{cases}$

\section{APPLICATION OF CONDUCTION TRANSFORM IN BANK CUSTOMER BEHAVIOR ANALYSIS}

In June, the central bank announced that the interest rate on bank deposits could be raised to 1.1 times the benchmark interest rate. In order to attract depositors, other banks have followed up and substantially increased deposit interest rates. Banks raise deposit interest rates and lower loan interest rates so that they can better serve the real economy and realize the marketization of interest rates. Lowering loan interest rates and increasing money supply will promote investment and consumption, ultimately resulting in an increase in total output, which is conducive to stimulating economic growth. Reducing the loan interest rate lessens the burden of enterprises, especially the large and medium-sized enterprises whose 
production and development funds mainly depend on bank loans, therefore the change of interest rate will directly affect their costs and profits. However, if the difference between the rate of interest rate reduction and the rate of deflation is not large, it will have little impact on investment. Therefore, a moderate reduction in lending rates by the central bank will not lead to a sharp decline in bank profits. In order to increase the overall profit, the bank can increase the deposit interest rate and lower the loan interest rate. That is to say, it raises the current deposit interest rate to $6.35 \%$, and lowers the loan interest rate to $5.6 \%$.

\section{A. Determination of active transformation}

In this case, the active transformation is

$\varphi_{1}$ : Raise the current deposit rate from $0.35 \%$ to $6.35 \%$.

$\varphi_{2}$ : The lending rate has been reduced from 5.9\% to 5.6\%.

The two information elements involved in active transformation $\varphi_{1}$ and $\varphi_{2}$ are $I_{\text {dep }}$ and $I_{\text {loan }}$, which are expressed in primitive form as :

$$
\begin{aligned}
& I_{\text {dep }}=\left(\begin{array}{lll}
O_{\text {dep }}, & c_{\text {dep }}, & v_{\text {dep }}
\end{array}\right) \\
& =\text { (deposit, interestrate, } 0.35 \% \text { ) } \\
& I_{\text {loan }}=\left(O_{\text {loan }}, c_{\text {loan }}, \quad v_{\text {loan }}\right) \\
& =\text { (loan, interestrate, 5.90\%) }
\end{aligned}
$$

After active transformation:

$$
\begin{aligned}
& \varphi_{1} I_{\text {dep }}=I_{\text {dep }}^{\prime}=\left(O_{\text {dep }}, \quad c_{\text {dep }}, \quad v_{\text {dep }}^{\prime}\right) \\
& =\text { (deposit, interestrate, 6.35\%) } \\
& \varphi_{2} I_{\text {loan }}=I_{\text {loan }}^{\prime}=\left(O_{\text {loan }}, \quad c_{\text {loan }}, \quad v_{\text {loan }}^{\prime}\right)_{\text {[2] }} \\
& =\text { (loan, interestrate, 5.60\%) }
\end{aligned}
$$

\section{B. Obtaining Conduction Object Set and Conduction Feature} Set

In this paper, 10 active customers are selected from the bank's customers as the transmission object set under the bank's active transformation, namely $\left\{O_{1}, O_{2}, \cdots, O_{10}\right\}$.

According to whether it has an impact on bank profits, five characteristics of the conduction object are selected as the conduction feature set, that is, the conduction feature set.

(1) The average daily balance of a customer account $\left(c_{1}\right)$ (10,000 yuan per day): it refers to the sum of the daily deposit balances of the same account divided by the daily deposit balances of the statistical period, that is, the average daily deposit balances of the statistical period. It is very important to count the average daily balance of an account because it directly determines a number of funds available to the bank, which in turn directly affects the final profit of the bank.

(2) Transaction frequency $\left(c_{2}\right)$ (times/days): the number of customer transactions in a certain period of time.

(3) Transaction amount ( $\left.c_{3}\right)$ (10,000 yuan per day): a number of product or service purchased by customers in a certain period of time. Transaction amount can measure a number of funds in an account, which reflects the capital stock and liquidity of the account owner to a certain extent.

(4) Personal Loan $\left(c_{4}\right)$ (10,000 yuan per day): Renminbi quota for the turnover of funds required by the business activities for which customers apply for and issue bank loans.

(5) Customer loyalty $\left(C_{5}\right)$ : on behalf of the customer's satisfaction of and dependence on the products or services provided by the bank, the customer will continue to purchase products or services, and actively recommend them to others. Banks can maintain customer relationships at low cost and bring new customers and resources to banks. ${ }^{[2]}$

TABLE I. VAlues Of INFORMATION ElEMENTS BeFore AND AFTER TRANSFORMATION

\begin{tabular}{cccccccccccc}
\hline & & O1 & O2 & O3 & O4 & O5 & O6 & O7 & O8 & O9 & O10 \\
\hline 1 c1 & BC & 1.4 & 2.5 & 5.8 & 0.5 & 2 & 5 & 9.4 & 1.8 & 2.6 & 2.7 \\
& AC & 3.1 & 3.5 & 6.8 & 2.5 & 3.8 & 8 & 9 & 3.8 & 4.5 & 4.3 \\
c c 2 & BC & 2 & 3 & 4 & 2 & 3 & 4 & 6 & 3 & 2 & 3 \\
& AC & 5 & 5 & 6 & 5 & 5 & 7 & 5 & 5 & 6 & 5 \\
c c 3 & BC & 0.2 & 0.4 & 0.6 & 0.05 & 0.35 & 0.9 & 1 & 0.3 & 0.45 & 0.55 \\
\hline & AC & 1.1 & 1.5 & 2 & 1.02 & 1.6 & 1.9 & 2.5 & 1.2 & 1.45 & 1.55 \\
c c 4 & BC & 0 & 0.2 & 1 & 0 & 0.8 & 1 & 2 & 0 & 1.2 & 1.4 \\
& AC & 2.1 & 2.2 & 3 & 2.2 & 3 & 5 & 4 & 2.5 & 3 & 3.2 \\
c c 5 & BC & 2 & 3 & 3 & 1 & 3 & 4 & 6 & 2 & 3 & 3 \\
& AC & 4 & 5 & 5 & 5 & 5 & 6 & 5 & 5 & 6 & 5 \\
\hline
\end{tabular}

When banks implement active transformation, it will lead to transmission transformation of customer's transmission characteristics. The quantities of 10 customers before and after active transformation for conduction characteristics are shown in TABLE I. There BC is the abbreviation of "Before Change", and $\mathrm{AC}$ is the abbreviation of "After Change".

\section{Calculating Conduction Effects and Conductance}

The conduction effects of conduction characteristics caused by active transformations $\varphi_{1}$ and $\varphi_{2}$ of banks are calculated according to formula (6), as shown in TABLE II. Taking $\delta=0.01$ as an example, the support degree of each conduction characteristic is calculated by the formula (11). TABLE III has shown the results.

TABLE II. THE DIFFERENCE BETWEEN THE CONDUCTION CHARACTERISTICS OF THE DATA BEFORE AND AFTER THE TRANSFORMATION

\begin{tabular}{cccccc}
\hline & c1 & c 2 & c 3 & c 4 & c 5 \\
\hline O1 & 1.70 & 3.00 & 0.90 & 2.10 & 2.00 \\
O2 & 1.00 & 2.00 & 1.10 & 2.00 & 2.00 \\
O3 & 1.00 & 2.00 & 1.40 & 2.00 & 2.00 \\
O4 & 2.00 & 3.00 & 0.97 & 2.20 & 4.00 \\
O5 & 1.80 & 2.00 & 1.25 & 2.20 & 2.00 \\
O6 & 3.00 & 3.00 & 1.00 & 4.00 & 2.00 \\
O7 & -0.40 & -1.00 & -0.10 & 2.00 & -1.00 \\
O8 & 2.00 & 2.00 & 0.90 & 2.50 & 3.00 \\
O9 & 1.90 & 2.00 & 1.00 & 1.80 & 3.00 \\
O10 & 1.60 & 2.00 & 1.00 & 1.80 & 2.00 \\
\hline
\end{tabular}


TABLE III. CONDUCTING OBJects CONDUCTIVITy AND CONDUCTION RANGE

\begin{tabular}{|c|c|c|c|c|c|c|c|c|c|c|c|c|c|}
\hline & O1 & $\mathrm{O} 2$ & O3 & $\mathrm{O} 4$ & O5 & O6 & O7 & O8 & O9 & $\mathrm{O} 10$ & {$\left[\gamma_{j \min }, \gamma_{j \max }\right.$} & $\begin{array}{c}\text { Support degree } \\
\gamma_{i j}>0\end{array}$ & $\begin{array}{c}\text { Support degree } \\
\gamma_{i j}<0\end{array}$ \\
\hline $\mathrm{c} 1$ & 53.97 & 31.75 & 31.75 & 63.49 & 57.14 & 95.23 & -12.7 & 63.49 & 60.32 & 50.79 & {$[-12.70,95.2]$} & 0.9 & 0.1 \\
\hline с 2 & 95.24 & 63.49 & 63.49 & 95.24 & 63.49 & 95.24 & -31.75 & 63.49 & 63.49 & 63.49 & {$[-31.75,95.24]$} & 0.9 & 0.1 \\
\hline c 3 & 28.57 & 34.92 & 44.44 & 30.79 & 39.68 & 31.75 & -3.17 & 28.57 & 31.75 & 31.75 & {$[-3.17,44.44]$} & 0.9 & 0.1 \\
\hline c 4 & 66.67 & 63.49 & 63.49 & 69.84 & 69.84 & 126.98 & 63.49 & 79.37 & 57.14 & 57.14 & {$[57.14,126.98]$} & 1 & 0 \\
\hline c 5 & 63.49 & 63.49 & 63.49 & 126.98 & 63.49 & 63.49 & -31.75 & 95.24 & 95.24 & 63.49 & {$[-31.75,126.98]$} & 0.9 & 0.1 \\
\hline
\end{tabular}

\section{Calculate Conductance and Conduction Interval}

According to formula (7), the active variable of active conversion $\varphi_{1}$ and $\varphi_{2}$ is calculated as follows: $\Delta v_{1}=|6.35 \%-0.35 \%|=0.06$

$$
\Delta v_{2}=|5.6 \%-5.9 \%|=0.003
$$

We can assume that the importance of adjusting deposit and loan interest rates has always been based on the impact of changes in bank deposit and loan interest rates on bank returns. so we set: $\lambda_{1}=\lambda_{2}=0.5$

According to formula (9), the conductivity of conductive properties is $\gamma_{j}=\frac{u_{j}^{\prime}-u_{j}}{0.0315}, j=1,2, \cdots, 10$

The conductivity and conductivity interval of the conduction object with respect to conduction characteristics are shown in TABLE III.

\section{According to TABLE II and TABLE III, we can see that:}

(1) The "daily average balance" is the conduction characteristic of the positive conduction effect with $90 \%$ support rate. It shows that the change of interest rate can promote the average daily balance deposit.

(2) Transaction frequency is the conduction characteristic of positive conduction effect with $90 \%$ support rate, indicating that the change of interest rate can promote the frequency of bank transactions.

(3) The transaction amount is the conduction characteristic of positive conduction effect with $90 \%$ support. It shows that the change in interest rate can promote the volume of bank transactions.

(4) Personal loan is the conduction characteristic of positive conduction effect, and the support rate is $100 \%$. It shows that the change of interest rate has a great promoting effect on personal loans of banks.

(5) Personal loyalty is the conduction characteristic of positive conduction effect with $90 \%$ support rate. It demonstrates that the change of interest rate has a great effect on the personal loyalty of banks. ${ }^{[2-4]}$

Through the bank's active extension transformation, the conductivity of conduction characteristic "daily average balance" is between [-12.70,95.2], the conductivity of conduction characteristic "transaction frequency" is between [-
31.75,95.24] and the conductivity of conduction characteristic "transaction frequency" is between [-31.75,95.24]. Conductivity ranges from [-3.17, 44. 44] to [-31.75,126.98]. The conductivity of conduction characteristics of "personal loan" is [57.14, 126. 98], and that of "personal loyalty" is [$31.75,126.98]$. The results show that the change of interest rate has both positive and negative conduction effects, while the positive conduction effects of "average daily balance of accounts", "transaction frequency", "transaction amount" and "personal loyalty" are 0.9. The degree of support for the positive conduction effect of "personal loan" is 1.0, i.e. 10 customers. 10 customer support data ${ }^{[1-3]}$

\section{E. Quantitative or Qualitative Knowledge of Conduction Characteristics}

According to the actual situation of banks and the historical data, the optimal point of daily average balance variable is right endpoint 10; the optimal point of action frequency variable is right endpoint 8; the optimal point of quantitative change of transaction volume is right endpoint 3 ; the optimal point of personal loan is right endpoint 6; and the optimal point of change of personal loyalty variable is right endpoint 6 . As is shown in TABLE IV, the correlation before and after transformation is calculated by the formula (12). IV:

The following knowledge can be obtained from TABLE

(1) In terms of daily average balance, the value of correlation function changes from less than or equal to zero to more than zero, and the degree of support is 0.6; after conversion, six data changes positively;

(2) In terms of transaction frequency, the value of correlation function changes from less than or equal to zero to more than zero, and the degree of support is 0.9. Positive qualitative changes have taken place in nine data after conversion.

(3) In terms of transaction volume, the value of correlation function changes from less than or equal to zero to more than zero, and the degree of support is 1.0. Positive qualitative changes have taken place in 10 data after conversion.

(4) For personal loans, the value of correlation function changes from less than or equal to zero to more than zero, and the degree of support is 1.0. Ten data change qualitatively after conversion.

(5) In terms of customer loyalty, the value of correlation function changes from less than or equal to zero to more than zero, and the support degree is 0.8 . After the implementation 
of transformation, eight data have undergone qualitative changes.

TABLE IV. THE CORRELATION BEFORE AND AFTER TRANSFORMATION

\begin{tabular}{ccccccccccc}
\hline & \multicolumn{3}{c}{ c1 } & \multicolumn{2}{c}{ c 2 } & \multicolumn{2}{c}{ c 3 } & \multicolumn{2}{c}{ c 4 } & \multicolumn{2}{c}{ c 5} \\
\cline { 2 - 11 } & BC & AC & BC & AC & BC & AC & BC & AC & BC & AC \\
\hline O1 & -0.53 & 0.01 & -1.00 & 0.50 & -0.80 & 0.10 & -1.00 & 0.02 & -0.50 & 0.00 \\
O2 & -0.17 & 0.05 & -0.33 & 0.50 & -0.60 & 0.50 & -0.90 & 0.03 & -0.25 & 0.50 \\
O3 & 0.33 & 0.54 & 0.00 & 0.50 & -0.40 & 0.50 & -0.50 & 0.17 & -0.25 & 0.50 \\
O4 & -0.83 & -0.17 & -1.00 & 0.50 & -0.95 & 0.02 & -1.00 & 0.03 & -0.75 & 0.50 \\
O5 & -0.33 & 0.08 & -0.33 & 0.50 & -0.65 & 0.75 & -0.60 & 0.17 & -0.25 & 0.50 \\
O6 & 0.20 & 0.71 & 0.00 & 0.75 & -0.10 & 4.50 & -0.50 & 0.75 & 0.00 & 1.00 \\
O7 & 0.91 & 0.86 & 1.00 & 0.50 & 0.00 & 0.75 & 0.00 & 0.50 & 1.00 & 0.50 \\
O8 & -0.12 & 0.08 & -0.33 & 0.50 & -0.70 & 0.20 & -1.00 & 0.25 & -0.50 & 0.50 \\
O9 & -0.04 & 0.15 & 0.00 & 0.50 & -0.55 & 0.45 & -0.40 & 0.17 & -0.25 & 1.00 \\
O10 & -0.03 & 0.13 & -0.33 & 0.50 & -0.45 & 0.10 & -0.30 & 0.21 & -0.25 & 0.50 \\
\hline
\end{tabular}

In summary, this transformation has made a qualitative change in the transaction frequency, transaction volume and personal loan support of the three transmission characteristics. The support degree of the average daily balance of accounts is 0.6 , which shows that the impact on different depositors is different. For example, conservative customers are less affected by changes in bank interest rates, while radical customers are more affected by changes in bank interest rates. Customer loyalty support is 0.8 , which indicates that the influence of conduction transformation on different customer loyalty has increased or decreased. For example, for the seventh customer, customer loyalty is 6 before the change and 5 after the change, which reveals that the loyalty of high-end customers to the bank is lower than that of other customer groups $^{[2-3]}$.

The impact of changes in bank interest rates on the banking market is negative in the short run because the interest income of banks decreases with the increase of deposit interest rates and the decrease of loan interest rates. However, in the long run, the interest income of banks decreases with the increase of deposit interest rates, namely the loan interest rates decrease with increasing deposits; more people apply for loans, and the demand for loans becomes positive. The increase of deposits and loans will gradually compensate for the reduced interest income due to the adjustment of interest rates, and at the same time activate the banking business. It shows that the conduction transformation of the influence of the change of bank interest rate on the bank market is effective.

\section{CONCLUSION}

Based on the theory of conduction transformation, this paper analyzes the extension transfer brought by bank adjustment of deposit interest rate and loan interest rate conversion. The effects of interest rate changes on the banking market are determined by the extraction of conduction objects and conduction characteristics, calculating conductivity and support. Through the analysis of specific cases, we can obtain an understanding of the quantitative and qualitative changes through conduction transformation. Through the analysis of transduction correlation, the positive impact of interest rate changes on the banking industry is verified. Extension transduction transformation is effective and it can activate the banking business and create greater benefits for the banks.

\section{REFERENCES}

[1] Yang Chunyan, Li Xiaomei, Li Yang. Research on Customer Value Based on Conductive Transformations[J]. Mathematics in Practice and Theory, 2012, 42(9): 142-147.

[2] Lin Li, Qiongzi Qin, Xiaobo Wang, Hong Gao."Bank Customers' Action Analysis Based on Conductive Transformation", MATEC Web of Conferences, 2018

[3] pt.slideshare.net. Internet Source

[4] Kanji Akahori. "Evaluation of Educational Computer Software in Japan (I): Methods and Results", PLET: Programmed Learning \&Educational Technology, 2006.

[5] Ma Yongzhi, Ding Yi, Gao Hong, Liu Wei. Logistics Market Segmentation Based on Extension Classification[C] // Proceeding of International Conference on Information Management, Innovation Management and Industrial Engineering. Xi'an, China: IEEE Press, 2013 (2): 216-219.

[6] Ding, Y., H. Gao, and W. Liu. "A Personalized Recommendation Algorithm Based on Extenics." International Symposium on Extenics \& Innovation Methods 2013.

[7] Ke Q , Dafang Z , University H , et al. Steganography for 3D Model Based on Frame Transform and HMM Model in Wavelet Domain[J]. Journal of Computer-Aided Design \& Computer Graphics, 2010, 22(8):1406-1411.

[8] QIU Baozhi, CHEN Xu. Image Segmentation Technology of Vehicle Collision Zone in Traffic Accident [J]. Computer simulation, 2013,30 (1): $215-218$. 